\title{
The Development of Episodic Memory: Lifespan Lessons
}

\author{
Yee Lee Shing ${ }^{1,2}$ and Ulman Lindenberger ${ }^{1}$ \\ ${ }^{1}$ Center for Lifespan Psychology, Max Planck Institute for Human Development \\ and ${ }^{2}$ Humboldt University, Berlin
}

ABSTRACT-This article looks at the development of episodic memory (EM) in children from a lifespan perspective, focusing on studies that directly compare children's patterns of memory performance to those of older adults. With training, children show greater improvements and higher levels of asymptotic performance than older adults even when they initially perform at the same or lower levels. Thus, the plasticity of EM appears to be greater in children than in older adults. Next, the article describes the two-component model of EM development, which delineates sets of mechanisms that may underlie EM differences between children and older adults. According to this model, EM requires the interaction between associative and strategic components. It posits that the associative component of $\mathrm{EM}$ is relatively mature by middle childhood and declines in old age. The strategic component of EM matures later than the associative component and also declines in old age. Empirical evidence supports the model, and the article discusses its relation to recent findings in developmental psychology and neuroscience. The article concludes that a lifespan perspective on EM helps to delineate the differences, commonalities, and dependencies among mechanisms that regulate its function and development.

The authors thank the late Paul Baltes, Lars Bäckman, Yvonne Brehmer, Chris Hertzog, Shu-Chen Li, Viktor Müller, Moshe NavehBenjamin, Timo von Oertzen, Markus Werkle-Bergner, and Hubert Zimmer for productive discussions. This article was written while UL was a Fellow at the Center for Advanced Study in the Behavioral Sciences at Stanford University.

Correspondence concerning this article should be addressed to Yee Lee Shing, Max Planck Institute for Human Development, Lentzeallee 94, 14195 Berlin, Germany; e-mail: yshing@mpib-berlin. mpg.de.

(c) 2011 The Authors

Child Development Perspectives ๑ 2011 The Society for Research in Child Development
KEYWORDS-episodic memory; binding; strategy use; lifespan psychology; child development; aging

Episodic memory (EM) is the conscious remembering of events, happenings, and situations relating the past, present, and future (e.g., Tulving, 2002). Researchers in cognitive development and cognitive aging have been working on understanding how memory develops and changes within confined age periods (for reviews, see Kausler, 1994; Schneider \& Pressley, 1997). However, scholars have invested remarkably little effort in directly examining and integrating the mechanisms underlying memory changes across the lifespan.

In this article, we highlight two major findings from investigations of EM that include children and older adults within the same study. Most of these studies are informed by the metatheoretical framework of lifespan psychology (Baltes, 1987; Baltes, Lindenberger, \& Staudinger, 2006). This framework assumes that sets of mechanisms related to maturation, senescence, and learning mutually enrich and constrain each other throughout the lifespan and that it is best to understand and study them as interacting forces driving the development of brain and behavior (cf. Craik \& Bialystok, 2006). As we will try to show, a lifespan perspective on EM helps to delineate the differences, commonalities, and dependencies among mechanisms that regulate its function and development.

\section{LESSON 1: LIFESPAN DIFFERENCES IN MEMORY PLASTICITY}

Episodic memory ability grows during childhood and adolescence and declines during old age (e.g., Li et al., 2004). However, this inverse U-shaped relation between memory performance and age tells us little about its robustness against variations in developmental context. Hence, similar to neuroscientists, lifespan researchers focus on plasticity and seek to 
complement descriptive knowledge about average age trends with a systematic exploration of the malleability of these age trends through intervention.

In this vein, Baltes and colleagues (Baltes, 1987; Lindenberger \& Baltes, 1995) distinguished three levels of performance: baseline performance, baseline plasticity, and developmental plasticity. Baseline performance is an individual's initial level of performance on a given task without external intervention. Baseline plasticity, also subsumed under flexibility by Lövdén, Bäckman, Lindenberger, Schaefer, and Schmiedek (2010), is the upper range of an individual's performance potential when he or she receives additional resources (such as instruction of a taskrelevant strategy). Developmental plasticity refers to a further strengthening of baseline plasticity attained through conditions that fully activate an individual's cognitive resources (such as through extensive practice that optimizes use of strategy). The distinction between baseline and developmental plasticity somewhat resembles Vygotsky's (1978) zone of proximal development, which puts more emphasis on the function of social interactions in promoting individual development. In comparison to singleshot comparative research, assessing developmental plasticity is a more direct and purer reflection of age-based changes in the psychological function under investigation.

Brehmer, Li, Müller, von Oertzen, and Lindenberger (2007) is one of the few studies that directly compared memory plasticity from middle childhood to early old age. The authors used a multiphase training design consisting of baseline assessment, strategy instruction, and strategy practice to compare the plasticity of EM performance in younger children aged 9-10, older children aged 11-12, younger adults aged 20-25, and older adults aged 6578. The participants learned and practiced the method of loci, an imagery-based mnemonic technique, to encode and retrieve words by location cues. Children performed at similar levels as older adults at baseline and after receiving instruction in the strategy (see Panel a of Figure 1). However, children profited considerably more than older adults from subsequent practice, leading to a magnification of age differences between children and older adults over the course of the experiment.

According to the authors, the instruction gains they measured indicated individuals' ability to use a new mnemonic strategy to actively organize learning materials, hence reflecting differences in baseline plasticity. Practice gains, on the other hand, reflected individuals' latent potential for optimizing the formation and retrieval of new associations, hence reflecting differences in developmental plasticity. These findings suggest that children in middle childhood and older adults differ little in their baseline performance and baseline plasticity, but that children possess greater developmental plasticity than older adults in EM performance, as the differential training gains revealed.

In a follow-up study with the same sample, Brehmer et al. (2008) examined the long-term maintenance of the mnemonic strategy 11 months after the completion of the original training study (see Panel b of Figure 1). They tested maintenance perfor-
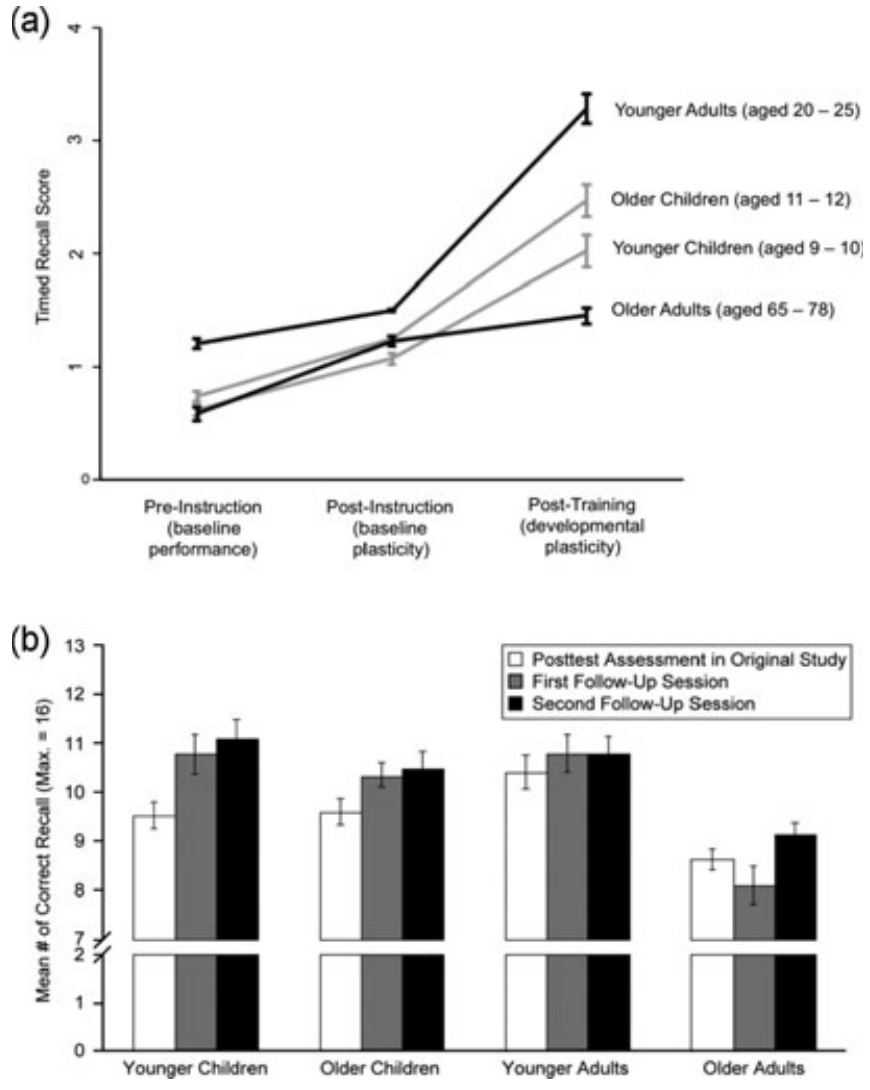

Figure 1. Panel a: Lesson 1 from lifespan comparisons: The plasticity of episodic memory is greater in children than in older adults. Panel b: Average number of correctly recalled words as a function of session and age group.

Note. In Panel a, memory performance refers to correctly recalled items over encoding time. Postinstruction scores for younger adults cannot be interpreted because of ceiling effects; all other data points can be interpreted. Error bars represent standard errors. In Panel b, recall performance is plotted separately for each age group. The white bars represent performance (number of correctly recalled words) in the posttest session of the original study (Brehmer et al., 2007), the gray bars represent performance in the first follow-up session (i.e., without mnemonic reinstruction), and the black bars represent the performance in the second follow-up session (i.e., after reinstruction in the mnemonic technique). Error bars indicate standard errors of the mean. Children (now aged 10-11 and 12-13) improved in skilled episodic memory performance 11 months after training without the need for reinstruction, presumably pointing to a powerful alliance between learning and maturation in middle and late childhood. Older adults showed decreasing trend in their memory performance 11 months after training, but improved further after reinstruction. Figure 1 is adapted from Brehmer et al. (2008).

mance in two sessions, the first without and the second with mnemonic reinstruction, to assess both spontaneous and reactive maintenance of skill. Children in both age groups spontaneously showed performance improvements beyond the level that they had attained 11 months earlier, and did not gain any further from reinstruction. In contrast, older adults showed decreased performance, and improved reliably from the first to the second retest session. These results suggest that developmental plasticity in middle childhood reflects a powerful alliance between learning and maturation that permitted enhancement of skilled EM 
performance without the need for reinstruction. Older adults, on the other hand, did not improve over time but were able to reactivate the skill they had acquired 11 months earlier. The overall pattern of findings suggests that the efficiency of cognitive interventions decreases from childhood to old age, pointing to possible practical implications (cf. Knudsen, Heckman, Cameron, \& Shonkoff, 2006).

In sum, the first lesson we can learn from lifespan research on EM is that the symmetry of the lifespan trajectory of EM performance is more apparent than real. Under suitable conditions for improvement, the performance patterns of children and older adults diverge (Figure 1), suggesting that the mechanisms that limit performance in old age are at least partially different from those that limit performance in childhood. In the following sections, we propose a two-component model of EM development that attempts to provide an initial framework for capturing these differences in underlying mechanisms.

\section{LESSON 2: THE LIFESPAN DISSOCIATION BETWEEN STRATEGIC AND ASSOCIATIVE COMPONENTS OF EPISODIC MEMORY}

Shing, Werkle-Bergner, Li, and Lindenberger (2008) introduced a two-component model of EM development across the lifespan (see also Shing et al., 2010; Werkle-Bergner, Müller, Li, \& Lindenberger, 2006). This model posits two evolving components of EM, one strategic and the other associative, and portrays the ontogeny of EM as the interaction between the two. The strategic component refers to cognitive control processes that aid and regulate memory functions at both encoding and retrieval. These processes include elaborating and organizing memory content at encoding, as well as specifying, verifying, monitoring, and evaluating relevant information at retrieval (cf. Simons \& Spiers, 2003). The associative component refers to binding mechanisms that integrate features of the memory content into coherent representations (Treisman, 1996; Zimmer, Mecklinger, \& Lindenberger, 2006). Neurocognitive models of EM postulate that the strategic component depends primarily on the prefrontal cortex (PFC), whereas the associative component mostly relies on the medial temporal lobes (MTL), especially the hippocampus (e.g., Moscovitch, 1992; Simons \& Spiers, 2003). Research has demonstrated that the PFC and MTL regions undergo differential changes from childhood to aging (for a review, see Werkle-Bergner et al., 2006). Earlier behavioral evidence, which we selectively summarize in Table 1 , as well as neuronal evidence, suggests that the distinction between strategic and associative components provides a productive platform for understanding the lifespan development of EM.

The model makes two main assumptions about the lifespan trajectories of each of the two components. First, it posits that the associative component of EM is relatively mature by middle childhood and declines with age. Second, it posits that the strategic component of EM matures later than the associative compo- nent (in late adolescence and young adulthood) and also declines with age.

To empirically test the developmental predictions emanating from the two-component model, Shing et al. (2008) conducted a lifespan study in which they manipulated the demands on associative and strategic components with a recognition memory task. Participants in the study encoded a list of word pairs. At retrieval, participants received some originally intact pairs, which appeared as pairs at the study phase; some new pairs not studied before; and some rearranged pairs, which included items that were presented at study but paired differently (see Naveh-Benjamin, 2000). Participants were supposed to accept the intact pairs and reject the new and rearranged pairs.

The study manipulated demands on the associative component by using word pairs with (a) low and (b) high associative demand (i.e., German-German "GG" vs. German-Malay "GM" words pairs). At the same time, instructions manipulated the demands on the strategic component by emphasizing (a) incidental item encoding, (b) intentional pair encoding, and (c) elaborative strategic encoding. A practice-based follow-up study for the GM condition sought to induce further improvements in participants' performance in this condition.

The results (see Figure 2) suggest that, in comparison to children, older adults showed slightly higher initial performance in item- and pair-instruction sessions, probably reflecting older adults' ability to make use of their larger repertoire of semantic knowledge to help with encoding new information. However, children showed higher performance gains from strategy instructions for the GG condition and from practice for the GM condition than older adults. Thus, children improved more than older adults in forming associations between memory features when provided with a combination of strategy instruction and taskrelevant practice. Older adults' performance gain was especially low in the high-associative-demand GM condition, supporting the hypothesis that the associative component is impaired among older adults (cf. Old \& Naveh-Benjamin, 2008).

Furthermore, inspecting the hits and false alarms rates separately revealed a pronounced lifespan dissociation of error patterns. Compared to the other age groups, older adults showed considerably greater difficulties in rejecting rearranged pairs that presumably elicited a strong familiarity response (see also Castel \& Craik, 2003). A comparison of effect sizes suggests that the age differences in false-alarm rates for rearranged pairs were especially pronounced in the high-associative-demand GM condition. Children, on the other hand, mainly showed lower hit rates than younger and older adults in both GG and GM conditions before strategy instruction. However, this age difference disappeared after strategy instruction and practice, again reflecting children's latent potential in associative binding once they overcome initial strategic deficiencies.

In sum, the second lesson we can learn from lifespan research on EM is that including older adults helps to elucidate the particular characteristics of EM in children, and vice versa. By 
Table 1

Converging Evidence of Lifespan Dissociation Between Strategic Component (Domains 1 and 2) and Associative Component (Domains 3, 4, and 5)

\begin{tabular}{|c|c|c|}
\hline Domains & Main findings & Selective reference(s) \\
\hline $\begin{array}{l}\text { (1) Executive functioning } \\
\text { (age of sample: covering 7-82) }\end{array}$ & $\begin{array}{l}\text { U-shaped or inverted U-shaped function (if performance is } \\
\text { measured as costs) of lifespan age pattern in tasks that } \\
\text { capture different aspects of executive functioning, including } \\
\text { inhibition, switching between task sets, and coordination of } \\
\text { cognitive processing in complex tasks }\end{array}$ & $\begin{array}{l}\text { Cepeda, Kramer, \& Gonzalez de } \\
\text { Sather (2001), De Luca et al. } \\
\text { (2003), Kray et al. (2004), } \\
\text { Reimers \& Maylor (2005), } \\
\text { Williams et al. (1999), } \\
\text { Zelazo et al. (2004) }\end{array}$ \\
\hline $\begin{array}{l}\text { (2) Prospective memory } \\
\text { (age of sample: } 7,10 \text {, younger } \\
\text { adults; older adults, mean age } 67 \text { ) }\end{array}$ & $\begin{array}{l}\text { Inverted U-shaped functions observed in phases of prospective } \\
\text { memory conceptualized as relying on executive control, } \\
\text { including intention formation, initiation, and execution }\end{array}$ & Kliegel et al. (2008) \\
\hline $\begin{array}{l}\text { (3) Binding in working memory } \\
\text { (age of sample: 8-10, 11-12, } \\
\text { younger adults; older adults, above 65) }\end{array}$ & $\begin{array}{l}\text { When item and binding changes were intermixed in a } \\
\text { change-detection task, older adults did less well than children } \\
\text { in binding trials. Changes in response biases related to } \\
\text { binding were more monotonic than U-shaped across the } \\
\text { lifespan }\end{array}$ & Cowan et al. (2006) \\
\hline (4) Visual search (age of sample: 6-89 years) & $\begin{array}{l}\text { Participants searched for circle targets that differed from } \\
\text { nontargets either in one feature or in the conjunction of two } \\
\text { features. Search was slower in children and older adults. } \\
\text { Older participants were especially slow in the conjunction } \\
\text { search with many targets and when target was absent from } \\
\text { display }\end{array}$ & Hommel et al. (2004) \\
\hline $\begin{array}{l}\text { (5) Attention } \\
\text { (age of sample: 6, 8, 10, 22, } 72 \text { years) }\end{array}$ & $\begin{array}{l}\text { Feature binding shows early maturation, but no deterioration in } \\
\text { later life (in contrary to the two-component framework). } \\
\text { Voluntary movement of spatial attention follows a pattern of } \\
\text { late maturation and significant decline in older adulthood }\end{array}$ & Trick \& Enns (1998) \\
\hline
\end{tabular}

including children and older adults in the same study, we attain a better understanding of what is special about each group's memory performance, both in relation to each other and in relation to adolescents and younger adults. Note that the contrasting patterns of performance of children and older adults often exist at similar levels of initial task proficiency, and thus cannot be dismissed as a byproduct of vastly differing performance levels. In the present case, our data are consistent with a model that posits divergent lifespan trajectories for strategic and associative components of EM.

\section{METHODOLOGICAL CHALLENGES IN TAKING A LIFESPAN APPROACH}

Lifespan comparisons exacerbate some of the methodological difficulties reflecting the complexities of human development. One main challenge is to find measures that assess the same or equivalent processes across the age ranges under investigation (Kagan, 1980; Labouvie, 1980). The lifespan studies we reviewed above track age differences in one function of EM, the ability to learn new associations, from middle childhood (beginning around 9 years of age) to old age. Relatively little is known about the ontogeny of more general aspects of EM at earlier ages, such as its autonoetic (capacity for mental time travel) and selfreferential nature (Tulving, 2002). Some building blocks of EM, such as novelty preference, develop at a much younger age (see Bauer, 2006). Flexible experimental paradigms are necessary in order to track the ontogeny of EM across wider age ranges including early childhood. In some cases, it may be necessary to relax the degree of experimental control to create conditions allowing for comparisons within individuals' functional range. For instance, researchers may need to adapt encoding times or stimuli set size to individuals' memory proficiency in order to avoid floor or ceiling effects.

It is also important to keep in mind potential differences in selectivity between different age groups. The extent to which a sample is representative of the population depends greatly on how the study draws participants. Participants of different ages also differ in a wealth of factors other than the phenomenon under study, such as personal characteristics, life history, and pre-experimental knowledge. Using microgenetic (short-term longitudinal), longitudinal, and training paradigms helps to overcome some of these confounds by ensuring that participants engage in similar processing while solving the task (Baltes et al., 2006). Furthermore, we recommend using multiple paradigms to assess constructs at the latent level and using multivariate statistical techniques (such as multilevel modeling) to better capture interindividual differences in cognitive functioning and change. In addition, the more widespread use of complementary methods across levels of analysis (e.g., combining behavioral and 


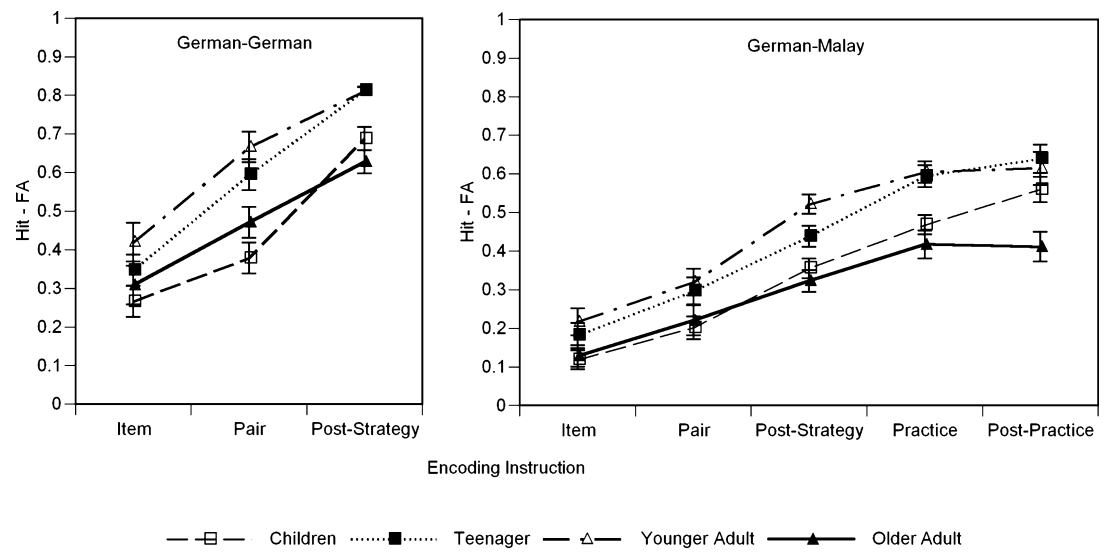

Figure 2. Lesson 2 from lifespan comparisons: The lifespan dissociation between strategic and associative components of episodic memory.

Note. Memory performance refers to correctly recognized pairs (hits) minus erroneously recognized lure pairs (false alarms). Here, the lure pairs consist of words that had been separately presented during encoding. As predicted, children (aged 10-12) overcame their initial strategy deficit through strategic instruction and subsequent practice, and eventually surpassed older adults, demonstrating the efficacy of their associative component. Adapted from Shing et al. (2008).

cognitive neuroscience methods) will help to uncover differences in cognitive processing masked by the compensatory behavioral strategies that different age groups adopt (cf. Lövdén et al., 2010; Reuter-Lorenz \& Cappell, 2008).

In sum, including children and older adults in the same study aggravates some methodological problems and interpretational ambiguities. However, the issues at hand are not fundamentally different from those involved in carrying out developmental research in general. In our judgment, the conceptual insights that come from lifespan comparisons are worth the added effort in research design and sampling.

\section{EPISODIC MEMORY ACROSS THE LIFESPAN: THE LARGER PICTURE}

\section{The Neural Level: PFC, MTL, and Their Interactions}

The two-component model of EM development is generally consistent with developmental evidence at the neural level. Anatomical studies show that the PFC in general, and its dorsolateral regions in particular, undergo profound maturational changes well into adolescence, whereas MTL regions mature at relatively faster rates (e.g., Gogtay et al., 2006; Sowell et al., 2003). At the functional level, neuroimaging studies suggest that slower development of memory for context and details is associated with the prolonged maturation of PFC regions but not the MTL regions (e.g., Chiu, Schmithorst, Brown, Holland, \& Dunn, 2006; Cycowicz, Friedman, \& Duff, 2003; Ofen et al., 2007). Thus, existing evidence suggests that the development of EM functions is paralleled by an age-related increase in PFC integrity, whereas memory-related MTL functioning remains relatively constant across middle childhood.

It is not yet clear how the different components of the EM network, which include both PFC and MTL, interact during ontogeny. At the behavioral level, children become more sophisticated in choosing and applying various memory strategies during encoding and retrieval with advancing age (see Schneider, 2011). Children also become increasingly proficient in encoding verbal information, demonstrating gains in remembering verbatim forms and an increased ability to extract gist information (e.g., Brainerd \& Reyna, 2004). Most of these age differences likely reflect changes in frontal rather than MTL functions, but direct evidence on relevant brain-behavior relations is not yet available. Furthermore, just as cognitive control does not refer to a unitary process, different memory-related strategic mechanisms may follow divergent developmental trajectories. These control mechanisms support the encoding of distinctive memory traces and the subsequent strategic search, retrieval, and evaluation of stored representations. Depending on the extent and type of control required, mechanisms may become fully functional earlier or later in the course of ontogeny (cf. Ghetti \& Angelini, 2008; Paz-Alonso, Ghetti, Donohue, Goodman, \& Bunge, 2008).

\section{The Evolution of Associative and Strategic Components during Childhood}

So far, studies motivated by the two-component model of EM development across the lifespan have not included children under the age of 8 years (e.g., Brehmer et al., 2007; Shing et al., 2008). Clearly, the model's implications extend into earlier childhood and require further specification. Binding mechanisms, or the process of integrating core content and contextual features of an event into a cohesive memory representation, are fundamentally important for the functioning of EM (Mitchell \& Johnson, 2009). In one of the few studies that examined binding in child development, Sluzenski, Newcombe, and Kovacs (2006) showed 4-year-olds, 6-year-olds, and young adults pictures of animals against arbitrary backgrounds, later testing them on their memory for the animals, the backgrounds, or both. Their results 
indicate that the ability to bind information in memory may progress significantly around 5-6 years of age (see also Lloyd, Doydum, \& Newcombe, 2009).

Researchers have suggested the development of binding as the underlying mechanism of preschoolers' difficulty in source monitoring (Sluzenski, Newcombe, \& Ottinger, 2004). Source monitoring refers to the ability to specify contextual information surrounding memory traces (Johnson, Hashtroudi, \& Lindsay, 1993). Children below 6 years of age tend to have difficulties in judging whether they performed or imagined an action (e.g., Day, Howie, \& Markham, 1998) and are more susceptible to false suggestions in eyewitness testimony because they easily confuse the sources of events (Ackil \& Zaragoza, 1995; Poole \& Lindsay, 1995). The ability to monitor sources in a variety of contexts improves rapidly between the ages of about 3 and 7 years (e.g., Drummey \& Newcombe, 2002; Ghetti, Lyons, Lazzarin, \& Cornoldi, 2008; Sluzenski et al., 2004). However, depending on a variety of task characteristics, improvement in source monitoring continues at least to 10 years (e.g., Ghetti, 2008; Roebers \& Schneider, 2005; Sussman, 2001).

It is unclear how much the development of source monitoring depends on PFC or MTL functioning (e.g., Cycowicz et al., 2003; Sluzenski et al., 2004; Sluzenski et al., 2006). One possibility is that initial development in source memory is mainly supported by the individual's rapidly developing binding ability. Later on, the development of the strategic component and, more importantly, the strengthening of the interactions between associative and strategic components may allow for not only more memory storage, but also enhancement of traces by including richer features and contextual information. Accordingly, development of memory abilities progresses early, beginning with processes relying more on the associative component such as novelty preferences, followed by more flexible forms of memory supported by the developmentally lagging strategic component (cf. de Haan, Mishkin, Baldeweg, \& Vargha-Khadem, 2006; Nelson, 2001).

\section{From Components to Mechanisms: Future Research Informed by the Two-Component Model}

An important avenue for future investigations will be to determine the exact nature of changes in the two memory components during child development and aging. In the Shing et al. (2008) study we discussed above, children showed lower hit rates than all other age groups before strategy instruction, but instruction and practice eliminated this age pattern. Failure to remember can be due to not having information available in memory, the deterioration of the memory trace following consolidation, or an inability to access available information (Tulving \& Pearlstone, 1966; see review in Shing et al., 2010). Although strategy intervention, as conducted in this study, mainly acted on encoding, it might have also aided children in better retrieving the appropriate memory traces through the imagery mediators they created. On the basis of the available data, we cannot distinguish to what extent the children's lower hit rate was due to encoding improp- erly the relations among stimuli, unsuccessful consolidation of new memory trace, or initially encoding the relations but having subsequent difficulty in retrieving them.

Older adults, on the other hand, showed persistently higher false-alarm rates (mostly accompanied with high ratings of confidence; see Shing, Werkle-Bergner, Li, \& Lindenberger, 2009) than children and young adults. Some researchers have hypothesized that a recall-to-reject retrieval mechanism enables resistance to a false alarm for a new item that shares characteristics with an original item (e.g., Dodson \& Schacter, 2001). Furthermore, neurocomputational models suggest that reductions in the efficacy of dopaminergic modulation lead to less distinctive memory representations in older adults (e.g., Li, Lindenberger, \& Sikström, 2001; Li, Naveh-Benjamin, \& Lindenberger, 2005). In light of this, in comparison to older adults, children from middle childhood onward have less difficulty in rejecting false events, possibly because of better strategic control at retrieval, more differentiated memory representations, or both. To delineate the mechanisms leading to older adults' increased false-alarm rates, future research should examine more closely lifespan age differences in retrieval processes, including those involved in the rejection of false memories.

In this article, we reviewed the main findings of studies that examine EM functioning across the lifespan. The two-component model of EM development portrays the dissociation between associative and strategic aspects of EM across the lifespan. The exact way in which these two components, and the corresponding MTL-PFC neural network, interact and develop throughout the lifespan remains to be elucidated, offering exciting venues for future research.

\section{REFERENCES}

Ackil, J. K., \& Zaragoza, M. S. (1995). Developmental differences in eyewitness suggestibility and memory for source. Journal of Experimental Child Psychology, 60, 57-83.

Baltes, P. B. (1987). Theoretical propositions of life-span developmental psychology: On the dynamics between growth and decline. Developmental Psychology, 23, 611-626.

Baltes, P. B., Lindenberger, U., \& Staudinger, U. M. (2006). Lifespan theory in developmental psychology. In W. Damon \& R. M. Lerner (Eds.), Handbook of child psychology: Vol. 1. Theoretical models of human development (6th ed., pp. 569-664). New York: Wiley.

Bauer, P. J. (2006). Constructing a past in infancy: A neurodevelopmental account. Trends in Cognitive Sciences, 10, 175-181.

Brainerd, C. J., \& Reyna, V. F. (2004). Fuzzy-trace theory and memory development. Developmental Review, 24, 396-439.

Brehmer, Y., Li, S.-C., Müller, V., von Oertzen, T., \& Lindenberger, U. (2007). Memory plasticity across the lifespan: Uncovering children's latent potential. Developmental Psychology, 43, 465478.

Brehmer, Y., Li, S.-C., Straube, B., Stoll, G., von Oertzen, T., Müller, V., et al. (2008). Comparing memory skill maintenance across the lifespan: Preservation in adults, increase in children. Psychology and Aging, 23, 227-238. 
Castel, A. D., \& Craik, F. I. M. (2003). The effects of aging and divided attention on memory for item and associative information. Psychology and Aging, 18, 873-885.

Cepeda, N. J., Kramer, A. F., \& Gonzalez de Sather, J. C. M. (2001). Changes in executive control across the life span: Examination of task-switching performance. Developmental Psychology, 37, 715730.

Chiu, C.-Y. P., Schmithorst, V. J., Brown, R. D., Holland, S. K., \& Dunn, S. (2006). Making memories: A cross-sectional investigation of episodic memory encoding in childhood using fMRI. Developmental Neuropsychology, 29, 321-340.

Cowan, N., Naveh-Benjamin, M., Kilb, A., \& Saults, J. S. (2006). Lifespan development of visual working memory: When is feature binding difficult. Developmental Psychology, 42, 1089-1102.

Craik, F. I. M., \& Bialystok, E. (2006). Cognition through the lifespan: Mechanisms of change. Trends in Cognitive Sciences, 10(3), 131139.

Cycowicz, Y. M., Friedman, D., \& Duff, M. (2003). Pictures and their colors: What do children remember. Journal of Cognitive Neuroscience, 150, 759-768.

Day, K., Howie, P., \& Markham, R. (1998). The role of similarity in developmental differences in source monitoring. British Journal of Developmental Psychology, 16, 219-232.

de Haan, M., Mishkin, M., Baldeweg, T., \& Vargha-Khadem, F. (2006). Human memory development and its dysfunction after early hippocampal injury. Trends in Neurosciences, 29, 374-381.

De Luca, C. R., Wood, S. J., Anderson, V., Buchanan, J.-A., Proffitt, T. M., Mahony, K., et al. (2003). Normative data from the Cantab. I: Development of executive function over the lifespan. Journal of Clinical and Experimental Neuropsychology, 25, 242-254.

Dodson, C. S., \& Schacter, D. L. (2001). "If I had said it I would've remembered it": Reducing false memories with a distinctiveness heuristic. Psychonomic Bulletin \& Review, 8, 155-166.

Drummey, A. B., \& Newcombe, N. S. (2002). Developmental changes in source memory. Developmental Science, 5, 502-513.

Ghetti, S. (2008). Rejection of false events in childhood. Curent Directions in Psychological Science, 17, 16-20.

Ghetti, S., \& Angelini, L. (2008). The development of recollection and familiarity in childhood and adolescence: Evidence from the dual-process signal detection model. Child Development, 79, 339-358.

Ghetti, S., Lyons, K. E., Lazzarin, F., \& Cornoldi, C. (2008). The development of metamemory monitoring during retrieval: The case of memory strength and memory absence. Journal of Experimental Child Psychology, 99, 157-181.

Gogtay, N., Nugent, T. F. I., Herman, D. H., Ordonez, A., Greenstein, D., Hayashi, K. M., et al. (2006). Dynamic mapping of normal human hippocampal development. Hippocampus, 16, 664-672.

Hommel, B., Li, K. Z. H., \& Li, S.-C. (2004). Visual search across the life span. Developmental Psychology, 40, 545-558.

Johnson, M. K., Hashtroudi, S., \& Lindsay, D. S. (1993). Source monitoring. Psychological Bulletin, 114, 3-28.

Kagan, J. (1980). Perspectives on continuity. In O. G. Brim \& J. Kagan (Eds.), Constancy and change in human development (pp. 26-74). Cambridge, MA: Harvard University Press.

Kausler, D. H. (1994). Learning and memory in normal aging. New York: Academic Press.

Kliegel, M., Mackinlay, R., \& Jäger, T. (2008). Complex prospective memory: Development across the lifespan and the role of task interruption. Developmental Psychology, 44, 612-617.
Knudsen, E. I., Heckman, J., Cameron, J. L., \& Shonkoff, J. P. (2006). Economic, neurobiological, and behavioral perspectives on building America's future workforce. Proceedings of the National Academy of Sciences of the United States of America, 103, 1015510162.

Kray, J., Eber, J., \& Lindenberger, U. (2004). Age differences in executive functioning across the lifespan: The role of verbalization in task preparation. Acta Psychologica, 115, 143-165.

Labouvie, E. W. (1980). Identity versus equivalence of psychological measures and constructs. In L. W. Poon (Ed.), Aging in the 1980s: Psychological issues (pp. 493-502). Washington, DC: American Psychological Association.

Li, S.-C., Lindenberger, U., Hommel, B., Aschersleben, G., Prinz, W., \& Baltes, P. B. (2004). Transformations in the couplings among intellectual abilities and constituent cognitive processes across the life span. Psychological Science, 15, 155-163.

Li, S.-C., Lindenberger, U., \& Sikström, S. (2001). Aging cognition: From neuromodulation to representation. Trends in Cognitive Sciences, 5(11), 479-486.

Li, S.-C., Naveh-Benjamin, M., \& Lindenberger, U. (2005). Aging neuromodulation impairs associative binding. Psychological Science, 16, 445-450.

Lindenberger, U., \& Baltes, P. B. (1995). Testing-the-limits and experimental simulation: Two methods to explicate the role of learning in development. Human Development, 38, 349-360.

Lloyd, M. E., Doydum, A. O., \& Newcombe, N. S. (2009). Memory binding in early childhood: Evidence for a retrieval deficit. Child Development, 80, 1321-1328.

Lövdén, M., Bäckman, L., Lindenberger, U., Schaefer, S., \& Schmiedek, F. (2010). A theoretical framework for the study of adult cognitive plasticity. Psychological Bulletin, 136, 659-676.

Mitchell, K. J., \& Johnson, M. K. (2009). Source monitoring 15 years later: What have we learned from fMRI about the neural mechanisms of source memory. Psychological Bulletin, 135, 638677.

Moscovitch, M. (1992). Memory and working-with-memory: A component process model based on modules and central systems. Journal of Cognitive Neuroscience, 4, 257-267.

Naveh-Benjamin, M. (2000). Adult age differences in memory performance: Tests of an associative deficit hypothesis. Journal of Experimental Psychology: Learning, Memory, and Cognition, 26, 1170-1187.

Nelson, C. A. (2001). The ontogeny of human memory: A cognitive neuroscience perspective. In M. H. Johnson, Y. Munakata, \& R. O. Gilmore (Eds.), Brain development and cognition: A reader (pp. 151-178). Oxford, UK: Blackwell.

Ofen, N., Kao, Y.-C., Sokol-Hessner, P., Kim, H., Whitfield-Gabrieli, S., \& Gabrieli, J. D. E. (2007). Development of the declarative memory system in the human brain. Nature Neuroscience, 10, 1198-1205.

Old, S. R., \& Naveh-Benjamin, M. (2008). Differential effects of age on item and associative measures of memory: A meta-analysis. Psychology and Aging, 23, 104-118.

Paz-Alonso, P. M., Ghetti, S., Donohue, S. E., Goodman, G. S., \& Bunge, S. A. (2008). Neurodevelopmental correlates of true and false recognition. Cerebral Cortex, 18, 2208-2216.

Poole, D. A., \& Lindsay, D. S. (1995). Interviewing preschoolers: Effects of nonsuggestive techniques, parental couching and leading question on reports of nonexperienced events. Journal of Experimental Child Psychology, 60, 129-154. 
Reimers, S., \& Maylor, E. A. (2005). Task switching across the life span: Effects of age on general and specific switch costs. Developmental Psychology, 41, 661-671.

Reuter-Lorenz, P. A., \& Cappell, K. A. (2008). Neurocognitive aging and the compensation hypothesis. Current Directions in Psychological Science, 17, 177-182.

Roebers, C. M., \& Schneider, W. (2005). The strategic regulation of children's memory and suggestibility. Journal of Experimental Child Psychology, 91, 24-44.

Schneider, W. (2011). Memory development in childhood. In U. Goswami (Ed.), The Wiley-Blackwell handbook of childhood cognitive development (2nd ed., pp. 347-376). West Sussex, UK: Wiley-Blackwell.

Schneider, W., \& Pressley, M. (1997). Memory development between two and twenty (2nd ed.). Mahwah, NJ: Erlbaum.

Shing, Y. L., Werkle-Bergner, M., Brehmer, Y., Müller, V., Li, S.-C., \& Lindenberger, U. (2010). Episodic memory across the lifespan: The contributions of associative and strategic components. Neuroscience and Biobehavioral Reviews, 34, 1080-1091.

Shing, Y. L., Werkle-Bergner, M., Li, S.-C., \& Lindenberger, U. (2008). Associative and strategic components of episodic memory: A lifespan dissociation. Journal of Experimental Psychology: General, 137, 495-513.

Shing, Y. L., Werkle-Bergner, M., Li, S.-C., \& Lindenberger, U. (2009). Committing memory errors with high confidence: Older adults do but children don't. Memory, 17, 169-179.

Simons, J. S., \& Spiers, H. J. (2003). Prefrontal and medial temporal lobe interactions in long-term memory. Nature Reviews Neuroscience, 4, 637-648.

Sluzenski, J., Newcombe, N., \& Kovacs, S. L. (2006). Binding, relational memory, and recall of naturalistic events: A developmental perspective. Journal of Experimental Psychology: Learning, Memory, and Cognition, 32, 89-100.
Sluzenski, J., Newcombe, N., \& Ottinger, W. (2004). Changes in reality monitoring and episodic memory in early childhood. Developmental Science, 7, 225-245.

Sowell, E. R., Peterson, B. S., Thompson, P. M., Welcome, S. E., Henkenius, A. L., \& Toga, A. W. (2003). Mapping cortical change across the human life span. Nature Neuroscience, 6, 309-314.

Sussman, A. L. (2001). Reality monitoring of performed and imagined interactive events: Developmental and contextual effects. Journal of Experimental Child Psychology, 79, 115-138.

Treisman, A. (1996). The binding problem. Current Opinions in Neurobiology, 6, 171-178.

Trick, L., \& Enns, J. (1998). Life span changes in attention: The visual search task. Cognitive Development, 13, 369-386.

Tulving, E. (2002). Episodic memory: From mind to brain. Annual Review of Psychology, 53, 1-25.

Tulving, E., \& Pearlstone, Z. (1966). Availability versus accessibility of information in memory for words. Journal of Verbal Learning and Verbal Behavior, 5, 381-391.

Vygotsky, L. S. (1978). Mind in society. Cambridge, MA: Harvard University Press.

Werkle-Bergner, M., Müller, V., Li, S.-C., \& Lindenberger, U. (2006). Cortical EEG correlates of successful memory encoding: Implications for lifespan comparisons. Neuroscience and Biobehavioral Reviews, 30, 839-854.

Williams, B. R., Ponesse, J. S., Schachar, R. J., \& Logan, G. D. (1999). Development of inhibitory control across the life span. Developmental Psychology, 35, 205-213.

Zelazo, P. D., Craik, F. I. M., \& Booth, L. (2004). Executive function across the life span. Acta Psychologica, 115, 167-184.

Zimmer, H. D., Mecklinger, A., \& Lindenberger, U. (Eds.). (2006). Handbook of binding and memory: Perspectives from cognitive neuroscience. Oxford, UK: Oxford University Press. 